\title{
Physicochemical Characterization of Solid Norfloxacin and Ciprofloxacin Metal Complexes: Spectroscopic and Thermal Studies
}

\author{
Basma A. A. Balboul* and Ebtihal S. Mohamed \\ Chemistry Department, Faculty of Science, Minia University, \\ El-Minia 61519, Egypt.
}

\begin{abstract}
SPECTROSCOPIC methods such as mass, infrared, nuclear $\checkmark$ magnetic resonance and X-ray diffraction in combination with thermal measurements are used to monitor and describe the physicochemical properties of the solid drug substances; the novel nor- and ciprofloxacin chromium(III) and zirconium (IV) metal complexes. The results support the formation of complexes with the formula $\left[\mathrm{Cr}(\mathrm{Nor})_{2}\right]\left(\mathrm{NO}_{3}\right)_{3} .4 \mathrm{H}_{2} \mathrm{O},\left[\mathrm{Cr}(\mathrm{Cip})_{2}\right] .7 \mathrm{H}_{2} \mathrm{O},\left[\mathrm{Zr}(\mathrm{Nor})_{2}\right] .3 .5$ $\mathrm{H}_{2} \mathrm{O}$ and $\left[\mathrm{Zr}(\mathrm{Cip})_{2}\right] .5 \mathrm{H}_{2} \mathrm{O}$. The FT/IR spectra of the isolated complexes suggest that norfloxacin and ciprofloxacin act as bidentate ligands through the ring carbonyl oxygen atom and one of the oxygen atoms of the carboxylic group. Thermal studies indicate that the complexes dehydrate at lower temperatures followed by pyrolytic decomposition at higher temperatures and the results show that zirconium complexes are more stable than chromium complexes.
\end{abstract}

Keywords: Ciprofloxacin, Norfloxacin, Spectroscopy and Thermal analysis .

Solid-state chemistry research plays a central role in the pharmaceutical industry. Solid pharmaceuticals exist as polymorphs, solvates, or amorphous forms, which collectively are described as solid forms. Most drugs are used in a crystalline form; the arrangement of molecules in a crystal determines its physical properties which can affect its performance. Quinolone antibiotics are complexing agents for a variety of metal ions ${ }^{(1)}$. Norfloxacin (Nor) is a synthetic, broad-spectrum antibacterial agent for oral administration. It is used to treat various bacterial infections such as urinary tract infections, gonorrhea and prostate infections. Ciprofloxacin (Cip) is another synthetic, broad-spectrum antibacterial drug used to treat pneumonia, bronchitis and some types of gonorrhea, diarrhea caused by bacteria, typhoid fever, prostate, sinus, and urinary tract infections.

Both Nor- and Ciprofloxacin are quinolone antibacterial agents, with 4-oxo3 -carboxylic acid groups that are essential for their bactericidal activity ${ }^{(1,2)}$. The design of metal-drug complexes is of particular interest in the pharmacological research.

*Corresponding author:

Tel: +20122438916 Fax: +2086 2342601 .

Email: Balboulbasma@gmail.com 
Metal combinations with pharmaceutical agents are known to improve the drugs activity and to decrease their toxicity. The coordinated metal ions in these antibiotics play an important role in maintaining proper structure and/or function.

The neutral quinolones in the zwitterionic state are potentially capable of forming simple complexes. In these complexes the quinolone coordinate to metal ions as a bidentate ligand via the ring carbonyl group at position 4 and through one of the oxygen atoms of the carboxylate group at position $3^{(3-7)}$.

Many authors studied the interactions of metal ions with quinolones ${ }^{(1,2)}$. They found that the absorption of the quinolone drugs is lowered when they are adminstered simultaneously with magnesium, aluminum, calcium, and zinc. The proposed reason for such behavior could be the chelate bonding of the quinolone to the metal. This was one of the reasons that many authors started to study the interactions of metal ions and quinolones ${ }^{(8-10)}$.

Therefore, the present investigation was designed to explore the physiochemical characteristics of four solid quinolone complexes. Up to the best of our knowledge, the synthesis and physicochemical properties of quinolones of Nor- and Ciprofloxacin with chromium (III) and zirconium (IV) metals have not been reported yet. To accomplish the present research objectives: (i) thermal events involved in the decomposition course were revealed by thermogravimetry and differential thermal analysis, (ii) chelation, proposed structure and crystallinity of the metal complexes were identified by Fourier-transform infrared spectroscopy, mass spectrometry, ${ }^{1} \mathrm{H}$-NMR spectroscopy and X-ray powder diffractometry.

\section{Experimental}

\section{Materials}

Norfloxacin and Ciprofloxacin used in this study were purchased from the (Medical Union Pharmaceuticals, Abu-Sultan, Ismailia, Egypt) and (Egyptian International Pharmaceutical Industrial Company EIPICO), respectively. All chemicals used for the preparation of the complexes were of analytical reagent grade, commercially available from different sources. $\mathrm{Cr}\left(\mathrm{NO}_{3}\right)_{3} \cdot 9 \mathrm{H}_{2} \mathrm{O}$ and $\mathrm{Zr}\left(\mathrm{NO}_{3}\right)_{4}$ are: $99 \%$ (BDH laboratory reagents, England). Norfloxacin and Ciprofloxacin are indicated throughout the text by the abbreviations (Nor) and (Cip), respectively.

\section{Synthesis}

Method 1: Preparation of solid chromium complex of norfloxacin

A solution of ( $1.0 \mathrm{mmol} .0 .40 \mathrm{~g})$ of $\mathrm{Cr}\left(\mathrm{NO}_{3}\right)_{3} .9 \mathrm{H}_{2} \mathrm{O}$ in $5 \mathrm{ml}$ of distilled water was added to a solution of $(1.0 \mathrm{mmol} .0 .319 \mathrm{~g})$ of norfloxacin ligand in $25 \mathrm{ml}$ acetone. The resulting mixture was heated at $50{ }^{\circ} \mathrm{C}$ under reflux on a water bath for about $12 \mathrm{hr}$ and then cooled. The precipitate formed was filtered off under vacuum, washed with boiling water then acetone and dried over $\mathrm{CaCl}_{2}$. The complex prepared is indicated throughout the text by the abbreviation (CrNor).

Egypt. J. Chem. 54, No.2 (2011) 
Method 2: Preparation of chromium ciprofloxacin complex and zirconium complexes of norfloxacin and ciprofloxacin

Appropriate quantity of ciprofloxacin $(0.5 \mathrm{mmol}, 0.165 \mathrm{~g})$ or norfloxacin $(0.5$ mmol. $0.159 \mathrm{~g}$ ) ligands was suspended in distilled water $(5 \mathrm{ml})$ which were then added to the solution of $\mathrm{Cr}\left(\mathrm{NO}_{3}\right)_{3} .9 \mathrm{H}_{2} \mathrm{O}(0.5 \mathrm{mmol}, 0.2 \mathrm{~g})$ or $\mathrm{Zr}\left(\mathrm{NO}_{3}\right)_{4}(0.5$ mmol, $0.169 \mathrm{~g})$ in distilled water $(5 \mathrm{ml})$. Triethylamine solution $(1 \mathrm{~mol} / \mathrm{l})$ was added dropwise, maintaining the $\mathrm{pH}$ between 7.5 and 8.0. The reaction mixture was stirred at room temperature for two days. The solid precipitate obtained was filtered off under vacuum, washed with distilled water and methanol, and dried. The prepared complexes are indicated throughout the text by the abbreviations (ZrNor), (CrCip) and (ZrCip).

Apparatus and techniques

Ex-situ FTIR spectra were taken of lightly loaded $(<1 \%)$ thin discs of $\mathrm{KBr}$ supported test materials at 4000 to $400 \mathrm{~cm}^{-1}$ with the resolution of $4 \mathrm{~cm}^{-1}$, using a model 410 Jasco FT-IR spectrophotometer (Japan).

The ${ }^{1} \mathrm{H}-\mathrm{NMR}$ spectra were determined on a GEMINI- $(200 \mathrm{MHz})$ spectrometer, Micro analytical Center, Cairo University and on JEOL- (500 $\mathrm{MHz}$ ) spectrometer, Faculty of Science, Alexandria University, using TMS as internal standard.

Mass spectra (MS) were taken on AEI MS 30 mass spectrometer at $70 \mathrm{eV}$.

Thermal analysis was performed by $30 \mathrm{H}$ Shimadzu analyzer (JAPAN). TG and DTA curves were recorded while heating a small portion $(10-15 \mathrm{mg})$ of the drug compound up to $800{ }^{\circ} \mathrm{C}$ at $10^{\circ} \mathrm{C} / \mathrm{min}$ in a $\mathrm{N}_{2}$ atmosphere $\left(20 \mathrm{~cm}^{3} / \mathrm{min}\right)$ of the test gas. A highly sintered $\alpha-\mathrm{Al}_{2} \mathrm{O}_{3}$ (Shimadzu Corp.) was the thermally inert reference material for the DTA. The abbreviation ML stands for mass loss.

X-ray powder diffraction patterns were obtained with a JSX-60 PA JEOL diffractometer (JAPAN) equipped with Ni-filtered $\mathrm{CuK} \alpha$ radiation $(\lambda=1.5416$ $\AA$ ). Based on scans in the range $4^{\circ} \leq 2 \theta \leq 60^{\circ}$, the $\mathrm{d}$-spacings and relative intensities $\left(\mathrm{I} / \mathrm{I}^{\circ}\right)$ were obtained.

\section{Results and Discussion}

The physical properties of (Nor) and (Cip) ligands and complexes are listed in Table 1. The melting points of the complexes are higher than that of the ligand revealing that the complexes are much more stable than ligands. All complexes are stable in air, and their solubility is much better than (Nor) and (Cip) itself, in water, methanol, chloroform, acetone, cyclohexane and 2- propanol. 
TABLE 1. Physical properties of the compounds of norfloxacin, ciprofloxacxin and their complexes.

\begin{tabular}{ccccc}
\hline $\begin{array}{c}\text { Molecular } \\
\text { formula }\end{array}$ & $\begin{array}{c}\text { Molecular } \\
\text { weight }\end{array}$ & $\begin{array}{c}\text { Yield } \\
(\boldsymbol{\%})\end{array}$ & Color & $\begin{array}{c}\text { mp } \\
\left({ }^{\circ} \mathbf{C}\right)\end{array}$ \\
\hline$(\mathrm{Nor}) \mathrm{C}_{16} \mathrm{H}_{18} \mathrm{FN}_{3} \mathrm{O}_{3}$ & 319 & - & yellow & $233-34$ \\
$\mathrm{C}_{32} \mathrm{H}_{44} \mathrm{~F}_{2} \mathrm{~N}_{9} \mathrm{O}_{19} \mathrm{Cr}$ & 772.63 & 77 & Dark green & $<300$ \\
$\mathrm{C}_{32} \mathrm{H}_{41} \mathrm{~F}_{2} \mathrm{~N}_{6} \mathrm{O}_{9.5} \mathrm{Zr}$ & 789.15 & 60 & yellow & $293-95$ \\
$(\mathrm{Cip}) \mathrm{C}_{17} \mathrm{H}_{18} \mathrm{FN}_{3} \mathrm{O}_{3}$ & 331.34 & - & White & \\
$\mathrm{C}_{34} \mathrm{H}_{50} \mathrm{~F}_{2} \mathrm{~N}_{6} \mathrm{O}_{13} \mathrm{Cr}$ & 745.3 & 73 & Pale green & $287-89$ \\
\hline $\mathrm{C}_{34} \mathrm{H}_{46} \mathrm{~F}_{2} \mathrm{~N}_{6} \mathrm{O}_{11} \mathrm{Zr}$ & 767.42 & 57 & Pale yellow & $292-94$ \\
\hline
\end{tabular}

FT/ IR spectra taken for the parents nor- and ciprofloxacin and their complexes with chromium and zirconium metals are compared in Fig. 1. TG and DTA curves of nor- and cipro -complexes obtained on heating (in nitrogen atmosphere) at $\left(10^{\circ} \mathrm{C} / \mathrm{min}\right)$ up to $800^{\circ} \mathrm{C}$ are given in Fig. 2 and 3, respectively. Table 2 summarizes the characteristics of thermal events encountered throughout during the decomposition courses of the four complexes under investigation. X-ray diffraction pattern obtained for (CrCip) complex is given in Fig. 4.

${ }^{1} \mathrm{H}-\mathrm{NMR}$ assignment for the parent (Nor) and Nor- metals complexes are listed in Table 3, whereas that for (Cip) and Cip- metals complexes are listed in (Table 4). The proposed structure of norfloxacin and its complex with chromium (III) (CrNor) and Zirconium (IV) (ZrNor) are shown in Scheme 1. The proposed structure of ciprofloxacin and its complex with Chromium (III) (CrCip) and Zirconium (IV) (ZrCip) are shown in Scheme 2.

Characterization of the $\mathrm{Cr}$-norfloxacin and $\mathrm{Cr}$ - ciprofloxacin complexes

The IR spectra of quinolones are quite complex due to the presence of numerous functional groups in the molecules. The IR spectra of quinolones are most representative in the region $1800-1300 \mathrm{~cm}^{-1(11)}$. Comparing the main IR frequencies of metal complexes with that of norfloxacin (Fig. 1A), the following was found (i) In the spectrum of the ligand (Nor), the two strong absorption peaks at 1727 and $1617 \mathrm{~cm}^{-1}$ are characteristic to (vCOOH) and (vCO), respectively $^{(12)}$ (ii) Different from the spectrum of the ligand (Nor), the band at $1727 \mathrm{~cm}^{-1}$ for the two complexes completely vanished due to deprotonation of $\mathrm{COOH}$ group and formation of $\mathrm{Cr}-\mathrm{O}$ and $\mathrm{Zr}-\mathrm{O}$ bond (Scheme 1). The peak at $1617 \mathrm{~cm}^{-1}$ was retained in the IR spectrum of CrNor and ZrNor but shifted to 1633 and $1635 \mathrm{~cm}^{-1}$, respectively. (iii) For the complexes, the bands positioned at the ranges of $1585-1500 \mathrm{~cm}^{-1}$ and $1480-1460 \mathrm{~cm}^{-1}$ may be attributed to the asymmetric and symmetric vibrations of the $-\mathrm{COO}$ group. So we proposed that the ligand norfloxacin interacted with the metal ions through bidentate chelating $^{(11)}$. This is consistent with the disappearance of the strong absorption at $1727 \mathrm{~cm}^{-1}$ in the spectra of complexes. The averaging effect took place between the single and double bonds on the carbonyl group owing to the coordination. (iv) New vibrating absorptions were observed in the range of 550$620 \mathrm{~cm}^{-1}$, which were characterized as the absorption of $\mathrm{M}-\mathrm{O}$ bonds ${ }^{(13)}$.

Egypt. J. Chem. 54, No.2 (2011) 


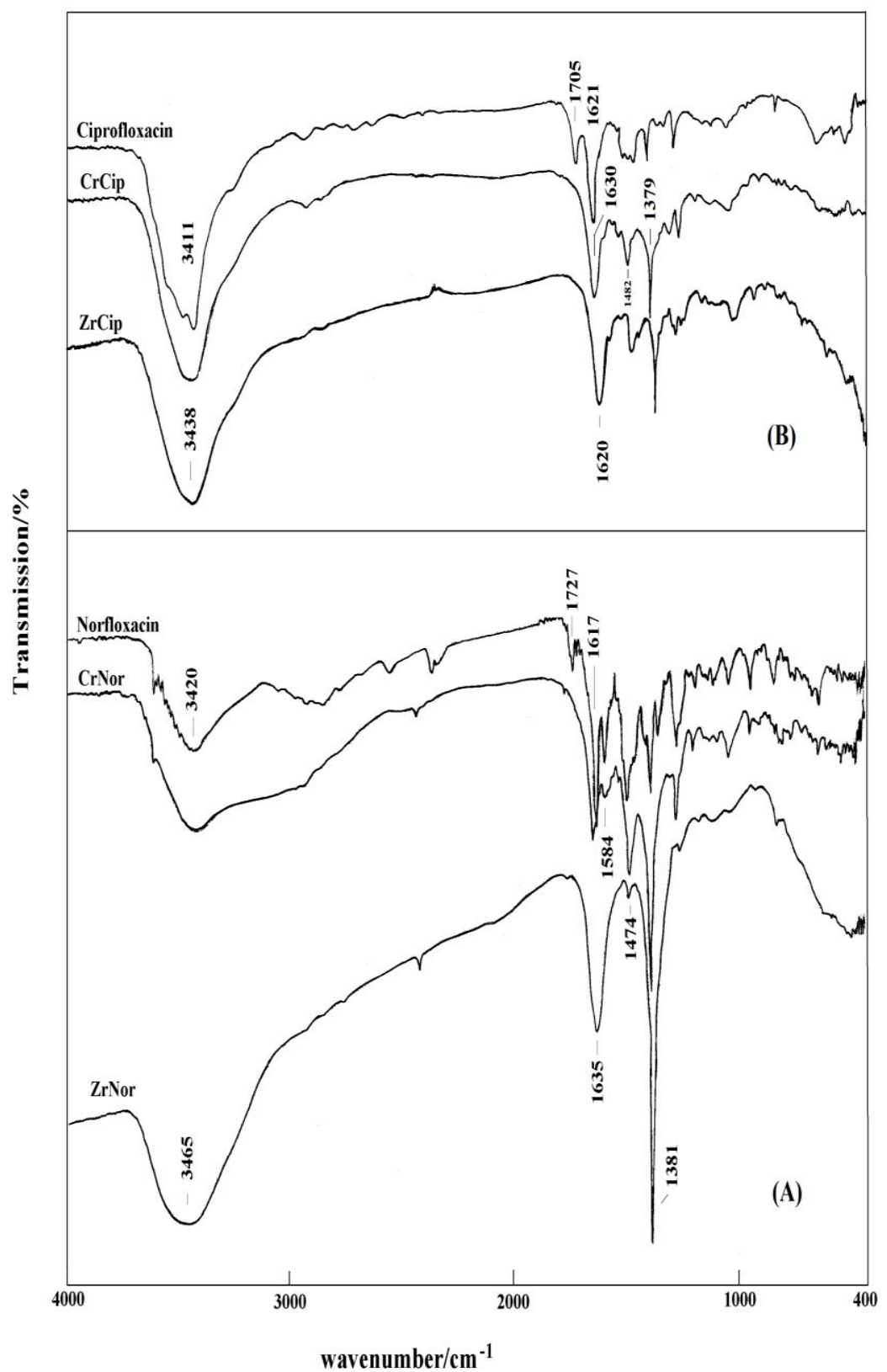

Fig. 1. FT/ IR spectra taken from (A) norfloxacin and its complexes with $\mathrm{Cr}$ and $\mathrm{Zr}$ metals and (B) ciprofloxacin and its complexes with $\mathrm{Cr}$ and $\mathrm{Zr}$ metals. 

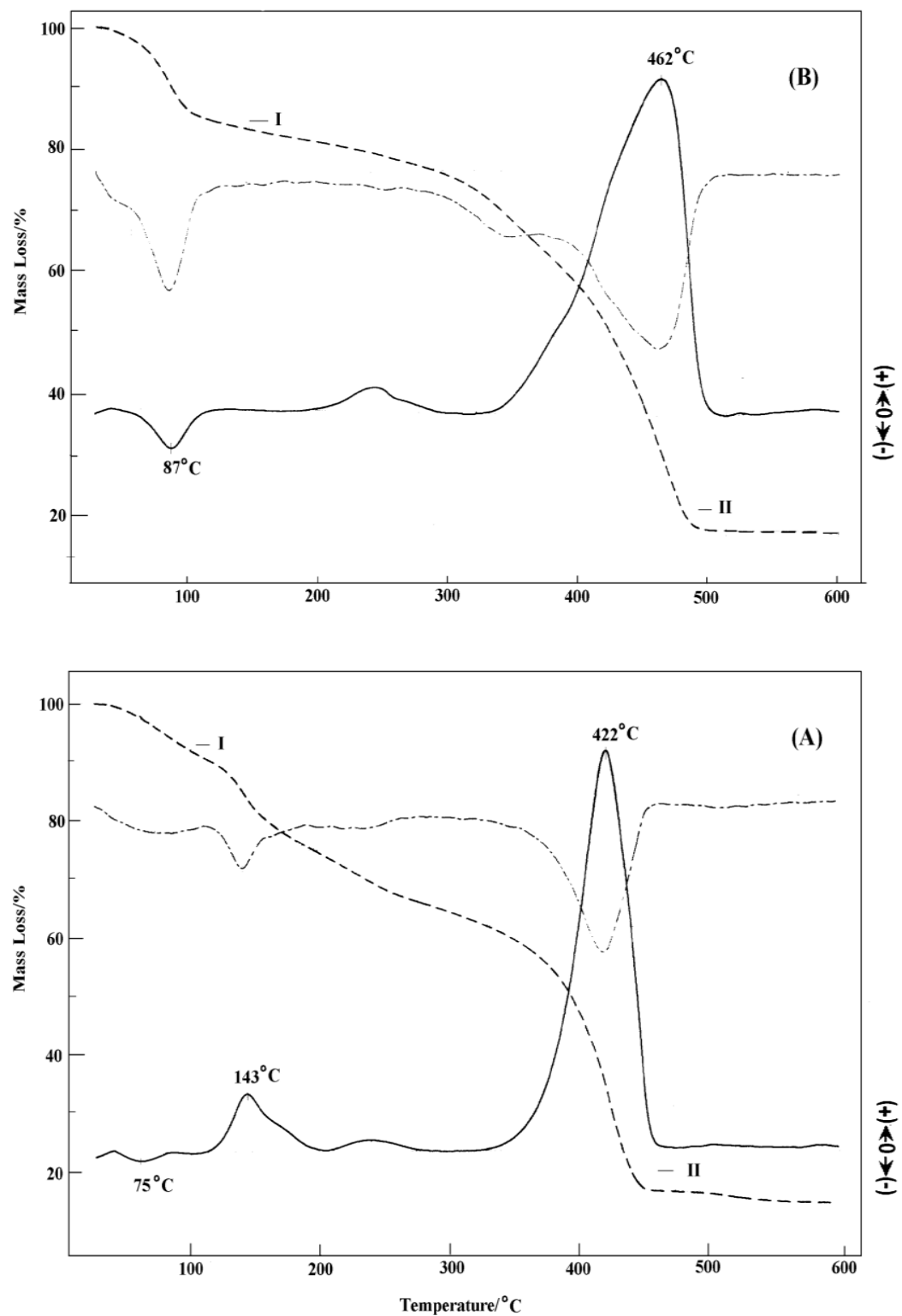

Fig. 2. TG(---), DTG(-•-) and DTA(-) curves obtained (at $\left.10^{\circ} \mathrm{C} / \mathrm{min}\right)$ for (A) CrNor complex (B) CrCip complex in a dynamic atmosphere of $\mathrm{N}_{2}\left(20 \mathrm{~cm}^{3} / \mathrm{min}\right)$. The Roman numerals (I-II) indicate locations where the thermal stages encountered are terminated, as further cited in Table 1. 

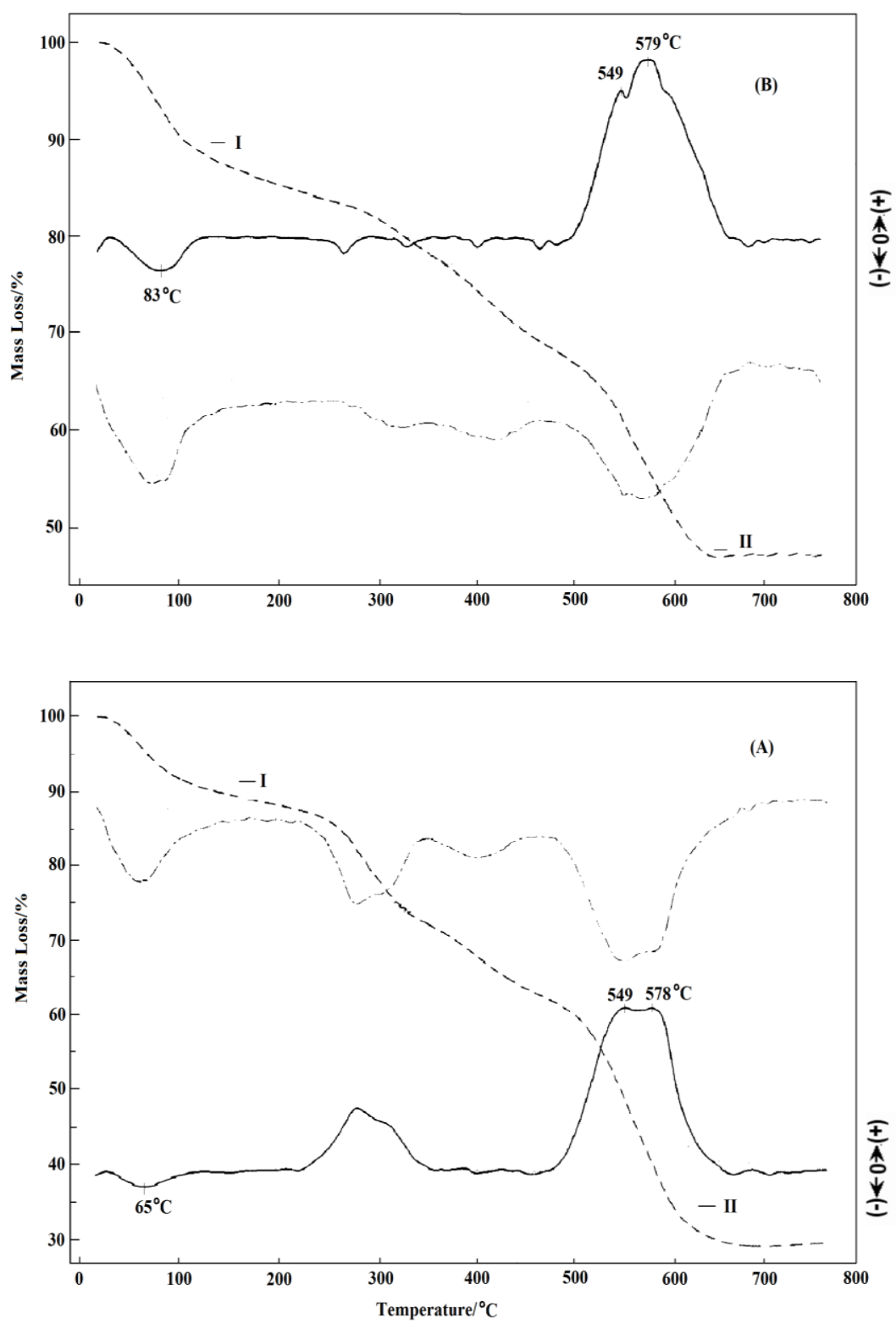

Fig. 3. TG(---), DTG(-•-) and DTA(-) curves obtained (at $10^{\circ} \mathrm{C} / \mathrm{min}$ ) for (A) ZrNor complex (B) ZrCip complex in a dynamic atmosphere of air (20 $\mathrm{cm}^{3} / \mathrm{min}$ ). The Roman numerals (I-II) indicate locations where the thermal stages encountered are terminated, as further cited in Table 1. 


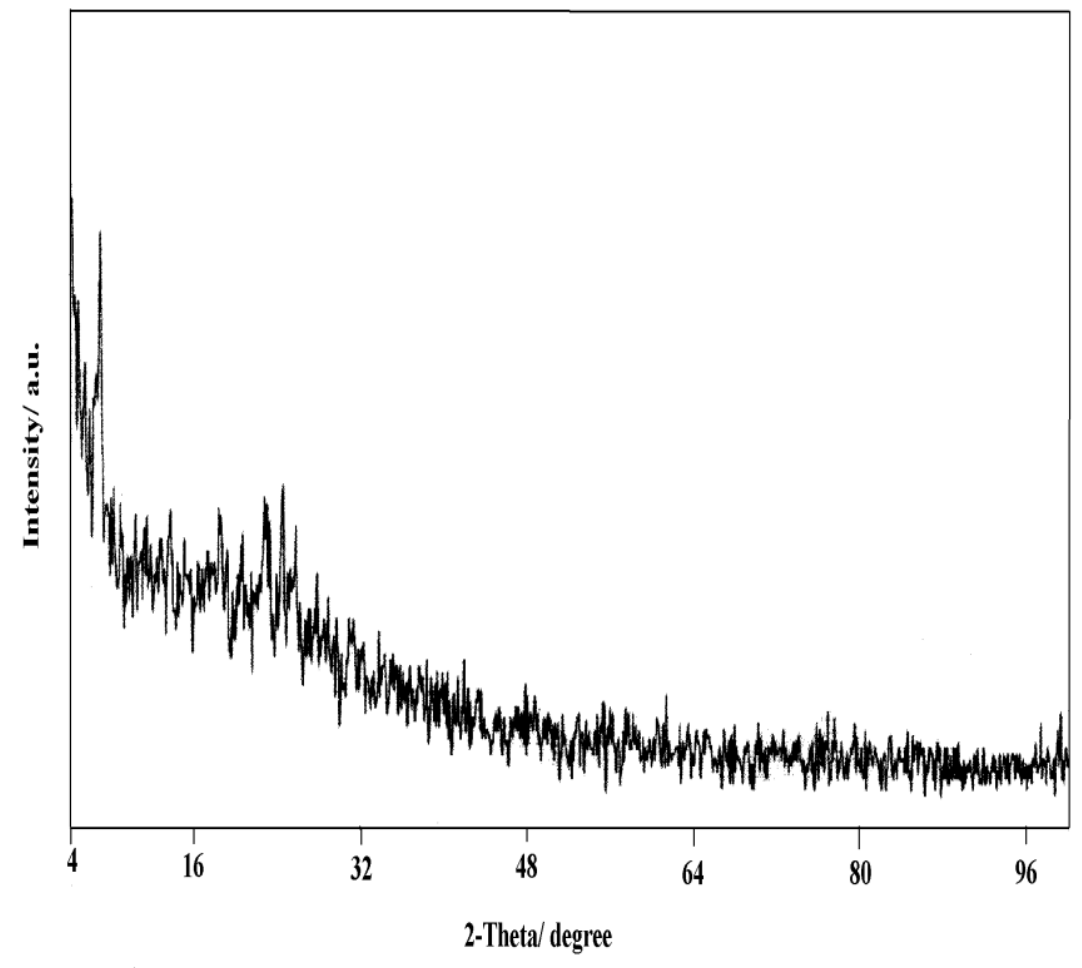

Fig. 4. X- ray diffraction pattern of chromium- ciprofloxacin complex (CrCip).

TABLE 2. Characteristics of thermal events encountered (Fig. 1) and (Fig. 2) throughout the decomposition course of Nor-and Cipro-metal complexes (at $10{ }^{\circ} \mathrm{C} / \mathrm{min}$ ) in $\mathrm{N}_{2}$.

\begin{tabular}{lcccc}
\hline \multicolumn{1}{c}{ Complex } & $\begin{array}{c}\text { Dehydration } \\
\text { temperature/ } \\
{ }^{\circ} \mathbf{C}\end{array}$ & $\begin{array}{c}\text { Mass loss/ } \\
\mathbf{\%}\end{array}$ & $\begin{array}{c}\text { Decomposition } \\
\text { temperature/ } \\
{ }^{\circ} \mathbf{C}\end{array}$ & $\begin{array}{c}\text { Total } \\
\text { Mass loss/ } \\
\%\end{array}$ \\
\hline$\left[\mathrm{Cr}(\mathrm{Nor})_{2}\left(\mathrm{NO}_{3}\right)_{3}\right] \cdot 4 \mathrm{H}_{2} \mathrm{O}$ & $50-110$ & 7.8 & $200-480$ & 83.7 \\
{$\left[\mathrm{Cr}(\mathrm{Cip})_{2}\right] \cdot 7 \mathrm{H}_{2} \mathrm{O}$} & $50-110$ & 15 & $140-520$ & 82 \\
{$\left[\mathrm{Zr}(\mathrm{Nor})_{2}\right] \cdot 3 \cdot 5 \mathrm{H}_{2} \mathrm{O}$} & $45-120$ & 8 & $200-800$ & 72 \\
{$\left[\mathrm{Zr}(\mathrm{Cip})_{2}\right] .5 \mathrm{H}_{2} \mathrm{O}$} & $50-120$ & 10.7 & $150-800$ & 52 \\
\hline
\end{tabular}


<smiles>CCn1cc(C(=O)O)c(=O)c2cc(F)c(N3[C]C(C)NCC3)cc21</smiles>
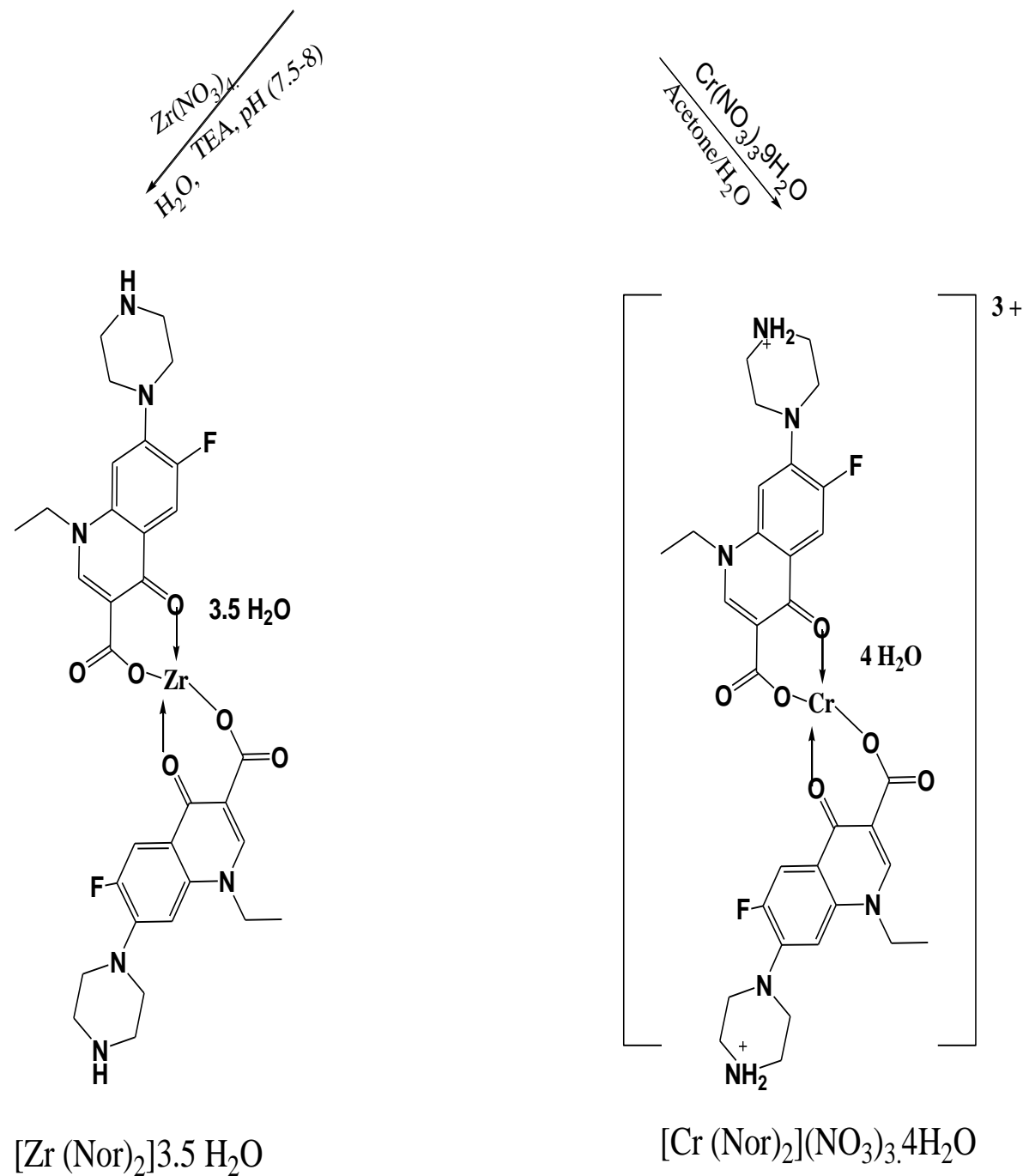

[Zr (Nor) $\left.)_{2}\right] 3.5 \mathrm{H}_{2} \mathrm{O}$

Scheme 1

Egypt. J. Chem. 54, No.2 (2011) 


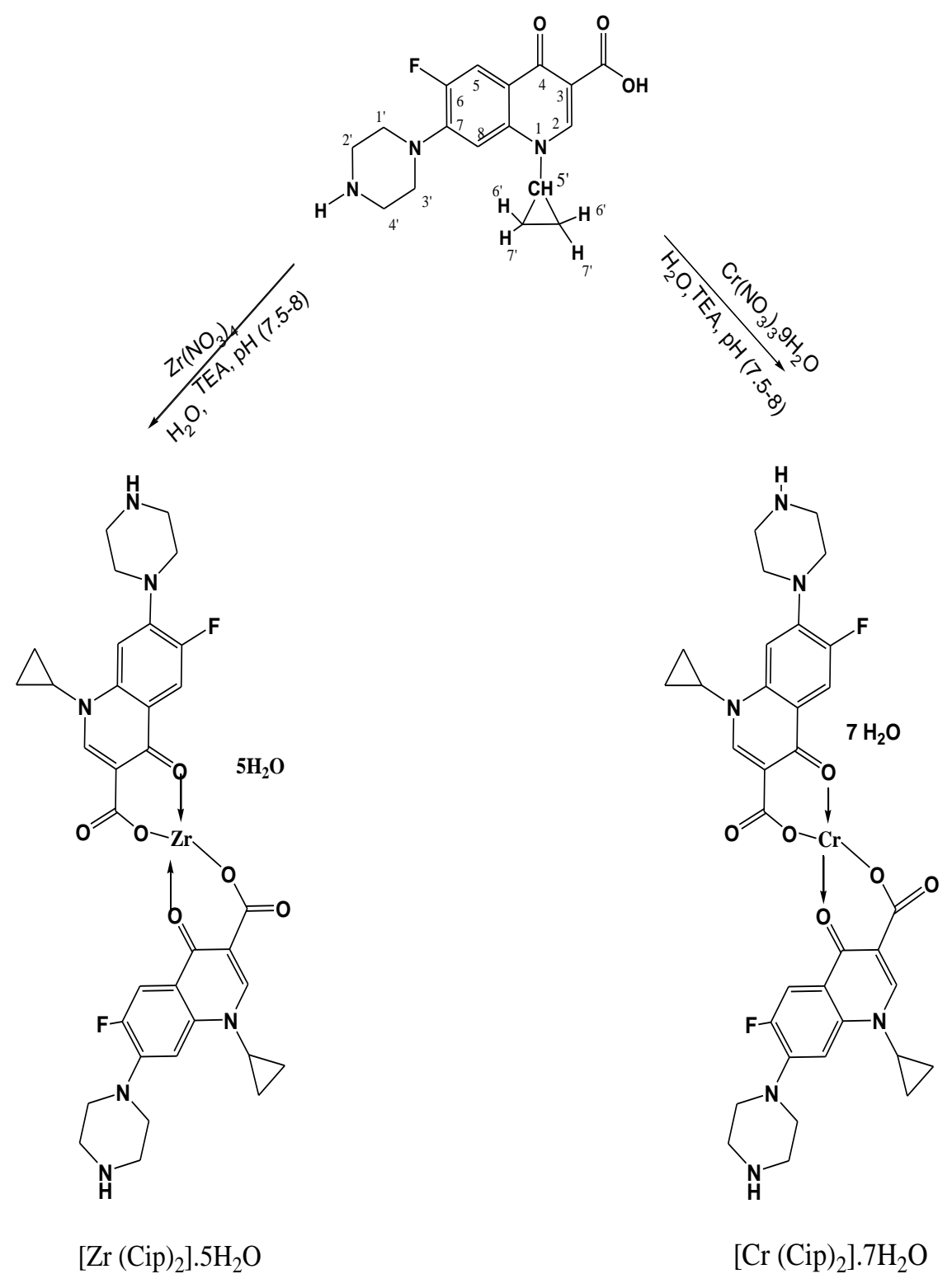

Scheme 2

Egypt. J. Chem. 54, No.2 (2011) 
TABLE 3. Assignment of ${ }^{1} \mathrm{H}-\mathrm{NMR}$ spectral data of norfloxacin, $\mathrm{Cr}$ - norfloxacin and $\mathrm{Zr}$-norfloxacin complexes in DMSO.

\begin{tabular}{cccc}
\hline Assignment & (Nor) & (CrNor) & (ZrNor) \\
CH3 & 1.41 & 1.25 & 1.44 \\
CH2 & 4.59 & 5.18 & 5.18 \\
$1^{\prime}, 3^{\prime}$ & $2.80-3.00$ & $2.90-3.80$ & $2.90-3.80$ \\
$2^{\prime}, 4^{\prime}$ & $3.10-3.30$ & $2.90-3.80$ & $2.90-4.40$ \\
H-2 & 8.92 & 8.49 & 8.99 \\
H-5 & 7.94 & 8.00 & 7.98 \\
H-8 & 7.12 & 7.25 & 7.32 \\
COOH & 15.00 & ----- & ----- \\
\hline
\end{tabular}

Acin and $\mathrm{Zr}$-norfloxacin complexes in DMSO.

TABLE 4. Assignment of ${ }^{1} \mathrm{H}$-NMR spectral data of free ciprofloxacin, Crciprofloxacin and $\mathrm{Zr}$ - ciprofloxacin complexes in DMSO.

\begin{tabular}{cccc}
\hline Assignment & (cip) & (Crcip) & (Zrcip) \\
\hline $1^{\prime}, 3^{\prime}$ & 3.56 & $2.70-3.00$ & $2.90-3.00$ \\
$2^{\prime}, 4^{\prime}$ & 3.66 & $3.30-3.50$ & $3.20-3.40$ \\
H-2 & 8.63 & 8.63 & 8.65 \\
H-5 & 7.49 & 7.85 & 7.89 \\
H-8 & 7.22 & 7.50 & 7.53 \\
$5^{\prime}$ & 3.80 & 3.80 & 3.85 \\
$6^{\prime}$ & 1.47 & $1.25-1.40$ & $1.29-1.35$ \\
7 & 1.22 & $1.00-1.20$ & $1.18-1.19$ \\
COOH & 15.00 & ---- & ---- \\
\hline
\end{tabular}

Assignment of ${ }^{1} \mathrm{H}-\mathrm{NMR}$ spectral data of free ciprofloxacin, $\mathrm{Cr}$ - ciprofloxacin and $\mathrm{Zr}$ ciprofloxacin complexes in DMSO .

Although the IR spectrum of Ciprofloxacin is different from that of norfloxacin, the spectra of their complexes are remarkably similar. The measured spectrum of the free (Cip) is similar to that reported by Turel et $a l^{(14)}$. The ketone $\mathrm{C}=\mathrm{O}$ of ( $\mathrm{Cip}$ ) was observed at $1705 \mathrm{~cm}^{-1}$, the $\mathrm{C}=\mathrm{C}$ bands in the region of 1600 and $1495 \mathrm{~cm}^{-1}$. The main feature of the (Cip) spectrum is the absence of the $(\mathrm{vCOOH})$ vibration, a behavior that is consistent with zwitterionic nature of ciprofloxacin established by x-ray diffraction. Two bands at 1452 and $1384 \mathrm{~cm}^{-1}$ in the spectrum of (Cip) for the asymmetric and symmetric stretching of the deprotonated carboxylate group, respectively. The shift observed of these bands to 1482 and $1379 \mathrm{~cm}^{-1}$, respectively, would be explained due to the coordination of Chromium metal to (Cip) ligand.

Thermal analysis results of the parent drugs norfloxacin ${ }^{(15)}$ show that norfloxacin is thermally stable in the temperature range $25-55^{\circ} \mathrm{C}$. Decomposition of the (Nor) started at $59{ }^{\circ} \mathrm{C}$ and finished at $726{ }^{\circ} \mathrm{C}$ with two stages. The first stage of decomposition occurs at maximum temperature of $116^{\circ} \mathrm{C}$ and is accompanied by ML of $8.75 \%$. The second stage of decomposition occur at three 
maxima 330, 423 and $654{ }^{\circ} \mathrm{C}$ and is accompanied by a ML of $83.73 \%$. The total ML from these two stages is equal to $92.46 \%$. Thermal analysis results of the parent drug ciprofloxacin ${ }^{(16)}$ show that its decomposition started at $104{ }^{\circ} \mathrm{C}$ and ended at $\sim 500{ }^{\circ} \mathrm{C}$. The first stage of decomposition occurs in the temperature range $104-140{ }^{\circ} \mathrm{C}$, due to sample dehydration, which was confirmed by a ML of $4.5 \%$. The second stage of decomposition occurs beyond $299{ }^{\circ} \mathrm{C}$ and is accompanied by a ML of $\sim 62 \%$.

Thermal analysis results (Fig. 2 and 3) reveal that the decomposition course of (CrNor) and (CrCip) commences near $50^{\circ} \mathrm{C}$ and terminates at $\geq 480{ }^{\circ} \mathrm{C}$ and $\geq 520^{\circ} \mathrm{C}$, respectively, encompassing poorly resolved exothermic events.

\section{Dehydration reactions}

TG and DTA results of (CrNor) and (CrCip) (Fig. 2) show broad endothermic events in the temperature range $50-110{ }^{\circ} \mathrm{C}$, characteristic to the removal of hydrated water. The ML accompanying event I in (CrNor) (7.4$7.8 \%)$ is rather close to that expected $(7.5 \%)$ for the release of four molecules of water (Table 2). Whereas, in the case of (CrCip) the ML at the end of event I is in the range $(14.8-15.3 \%)$ as that expected $(15 \%)$ for the removal of seven moles of water (Table 2).

\section{Decomposition reactions}

(CrNor) complex begins to decompose at $\sim\left(110-115{ }^{\circ} \mathrm{C}\right)$ through overlapped exothermic events bringing the total ML for (CrNor) (83- $84 \%$ ) and the total ML for (CrCip) (82.5- $83 \%$ ) are close to that $(83.9 \%)$ and $(81.8 \%)$, respectively, calculated for the formation of the final decomposition product of the green colored $\mathrm{Cr}_{2} \mathrm{O}_{3}$. The thermal events are resolved on the temperature scale of the DTA curve, but strongly overlapped on the temperature scale of the TG curve. It is worth mentioning that the decomposition course of these complexes is carried out in air atmosphere (results are not shown) to detect the impacts of different atmosphere (other than the inert $\mathrm{N}_{2}$ ) that may affect the kinetics of the decomposition reaction. The result revealed beyond doubt that there is no detectable difference between the thermal analysis results accompanying changing the applied atmosphere except that the decomposition events are kinetically enhanced in air atmosphere. It is almost completed in a narrower range of temperature $\left(110-430{ }^{\circ} \mathrm{C}\right)$ for (CrNor) and $\left(110-470{ }^{\circ} \mathrm{C}\right)$ for $(\mathrm{CrCip})$.

Characterization of the $\mathrm{Zr}$ - norfloxacin and $\mathrm{Zr}$ - ciprofloxacin complexes

In all spectra represented in Fig. $1 \mathrm{~A}$ and $\mathrm{B}$, the absorption bands in the region 3450 - 3200 could be assigned to the symmetric and asymmetric stretching vibrations of water molecules. The IR spectra of ( $\mathrm{ZrNor}$ ) and ( $\mathrm{ZrCip}$ ) complexes are compared in (Fig. 1A and B). The spectra show clearly the characteristic peaks of the complexes at frequencies similar as in case of $\mathrm{Cr}$ - complexes but shifted to higher or lower few wavenumbers due to coordination of Zirconium metal to (Nor) and (Cip) via the ring carbonyl group at position 4 and through one of the oxygen atoms of the carboxylate group at position 3 .

Egypt. J. Chem. 54, No.2 (2011) 
Thermal analysis results of (ZrNor) and (ZrCip) compounds (Fig. 3) indicate that the decomposition course of both complexes takes place in a wider temperature range than chromium complexes. The decomposition course commences near $40{ }^{\circ} \mathrm{C}$ and terminates at $\sim 700{ }^{\circ} \mathrm{C}$.

\section{Dehydration reactions}

The dehydration stage begins at low temperature $<40{ }^{\circ} \mathrm{C}$, not all water molecules are equivalently bonded. The weaker bonded water molecules in metal quinolones could be lost at very low temperature. This may be observed from the DTG curve, where the endothermic effect corresponding to the dehydration stage is poorly resolved into two peaks maximized at 35 and $59{ }^{\circ} \mathrm{C}$ in ( $\mathrm{ZrNor}$ ) and at 35 and $76{ }^{\circ} \mathrm{C}$ in ( $\left.\mathrm{ZrCip}\right)$, indicating the presence of two types of bonded water molecules. The ML accompanying the dehydration processes in (ZrNor) and (ZrCip) are (7.5- 8\%) and (10-10.7\%), respectively. The experimental ML indicates that (ZrNor) contains 3.5 molecules of hydrated water, whereas, (ZrCip) has 5 molecules of water.

\section{Decomposition reactions}

Decomposition reactions immediately commence occurring following the dehydration reactions at $\sim 150{ }^{\circ} \mathrm{C}$ involving overlapped exothermic events. The mass losses at the end of this stage in (ZrNor) and (ZrCip) complexes are ( 71 and $52 \%$ ) indicate that zirconium complexes are stable.

\section{$X$ - ray diffraction}

X-ray diffraction patterns recorded at $2 \theta=0$ - 90 range for all complexes show that all complexes are amorphous solids (results are not shown), except (CrCip) complex, has a poorly crystalline nature (Fig. 4).

\section{Mass spectrometry}

In the mass spectrometer, the sample is ionized to produce a charged molecule and a series of ionic fragments. The assortment of charged particles is then separated according to their mass to charge ratios $(\mathrm{m} / \mathrm{z})$ and displayed as a mass spectrum. Mass spectral data provide information about molecular mass if the molecular ion is identified whereas the fragmentation patterns give identification of unknowns and structural features.

The mass spectra detect the mass ions corresponds to the parent ligand drug (nor and cip ligands) at $\mathrm{m} / \mathrm{z}=320$ and 331, respectively. The appearance of nor and cip ligand as a fragment in mass spectroscopy of the prepared complexes is consistent with that was found in a previously prepared Ag-Nor complex ${ }^{(15)}$. The molecular ion peaks which correspond to metal- ligand fragments are also detected in various abundances as well as that corresponds to variable molecules of water ranging from 0.5 to 4.0 , some expected ions are not detected or present in very low intensity. In the mass spectrum of (CrNor) with the formula $\mathrm{C}_{32} \mathrm{H}_{44}$ $\mathrm{F}_{2} \mathrm{~N}_{9} \mathrm{O}_{19} \mathrm{Cr}_{2}$ the following mass peaks are detected at $\mathrm{m} / \mathrm{z}=922(10 \%), 320$ (12\%), whereas in (CrCip) with the formula $\mathrm{C}_{34} \mathrm{H}_{50} \mathrm{~F}_{2} \mathrm{~N}_{6} \mathrm{O}_{13} \mathrm{Cr}$, mass peaks at 838.7 (5\%), 349.3 (20\%), 332.0 (7\%). 
Similar fragments appeared in case of zirconium complexes. The mass spectrum of ( $\mathrm{ZrNor}$ ) with the formula $\mathrm{C}_{32} \mathrm{H}_{41} \mathrm{~F}_{2} \mathrm{~N}_{6} \mathrm{O}_{9.5} \mathrm{Zr}$, mass peaks at 789.4 (20\%), $319.15(100 \%)$, whereas the mass peaks of ( $\mathrm{ZrCip})$ with the formula $\mathrm{C}_{34} \mathrm{H}_{46} \mathrm{~F}_{2} \mathrm{~N}_{6} \mathrm{O}_{11} \mathrm{Zr}$, mass peaks at m/z $840(5 \%), 332(100 \%), 288(6 \%)$.

These results are consistent with the presence of direct metal- ligand bonding in chromium and zirconium complexes as well as the formation of a bidentate complex of the type of (2 ligand:1 metal).

In general, the fragmentation patterns give identification of unknowns and structural features. It is believed that the fragmentation pattern of the complexes occurs through stepwise removal of water, a ligand in addition to the metal leaving the fragment corresponding to the other ligand as the base peak $(100 \%$ intensity) in case of zirconium complexes of norfloxacin and ciprofloxacin. The following is a proposed fragmentation pattern for ( $\mathrm{ZrNor}$ ) complex:

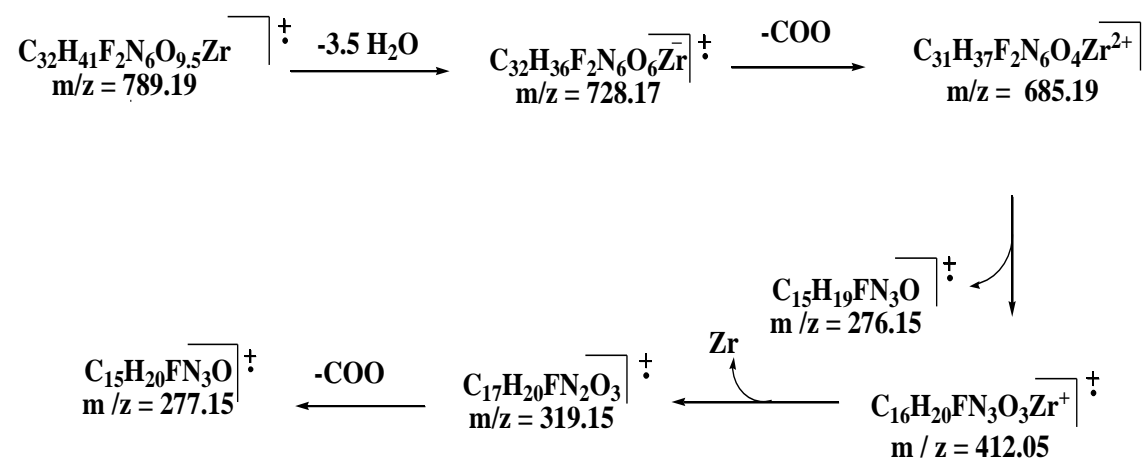

Nuclear magnetic resonance

Nuclear magnetic resonance $\left({ }^{1} \mathrm{H}\right.$ - NMR) spectroscopy is used to determine the structures of materials such as new drugs. NMR spectroscopy gives information about the environment in which the nuclei of atoms are found in molecules.

The ${ }^{1} \mathrm{H}-\mathrm{NMR}$ chemical shifts of the parent quinolones and the corresponding metal complexes are listed in Tables 3 and 4. The spectra of the complexes of (nor) and (cip) with both zirconium and chromium metals showed broad signals that were attributed to what is known as paramagnetic characters ${ }^{(17)}$. Generally, minor changes had been demonstrated in the chemical shifts of the prepared complexes on comparison with their corresponding signals in the parent quinolones. This was explained previously ${ }^{(17)}$ by the change in the counteranion or to a different association of the quinolone molecules. The ${ }^{1} \mathrm{H}-\mathrm{NMR}$ spectra of all the studied complexes showed lack of the characteristic - $\mathrm{COOH}$ signal at about $\delta=15 \mathrm{ppm}$, indicating that complexation occurs through the carboxylate and the $\mathrm{C}_{4}$ carbonyl group. The doublet characteristic for $\mathrm{H}-8$ in the complexes appeared at $\delta=7.25,7.31 \mathrm{ppm}$ for (CrNor) and (ZrNor), respectively (Table 3). 
Whereas in (CrCip) and (ZrCip) complexes, the signals appeared at about $\delta=7.5$ $\mathrm{ppm}$ (Table 4). The characteristic signal for H-5 appeared at about $\delta=8 \mathrm{ppm}$ for both (CrNor) and (ZrNor), while appeared at $\delta 7.85-7.90 \mathrm{ppm}$ in case of (CrCip) and (ZrCip) complexes, respectively. The singlet signal characteristic for $\mathrm{H}-2$ appeared at $\delta=9.0 \mathrm{ppm}$, that is downfield shifted by $\delta=0.2 \mathrm{ppm}$ than the corresponding proton in case of (CrNor) and (ZrNor), it appeared at about $\delta=$ 8.65 for the corresponding proton in both complexes of (Cip) that is downfield shifted about $\delta=0.15 \mathrm{ppm}$ from the parent ciprofloxacin $\mathrm{H}-2$ proton. There was found a downfield shift for the multiplet corresponding to the piperazine protons $\mathrm{H}-8$, where it appeared at $\delta=2.9-4 \mathrm{ppm}$ for the complexes (CrNor) and (ZrNor), and $\delta=3.2-3.6 \mathrm{ppm}$ for the corresponding ciprofloxacine complexes. Also, the ${ }^{1} \mathrm{H}-\mathrm{NMR}$ spectra showed the characteristic signals for both the $\mathrm{N}-\mathrm{CH}_{2} \mathrm{CH}_{3}$ and $\mathrm{N}$-cyclopropyl groups, but unfortunately, multiplicity could not be distinguished due to broadness of the signals.

\section{Conclusion}

Four new $\mathrm{Cr}(\mathrm{III})$ and $\mathrm{Zr}(\mathrm{IV})$ complexes of norfloxacin and ciprofloxacin have been synthesized. Spectroscopic and thermal analysis measurements help in drawing the following conclusions:

1. The interaction of $\mathrm{Cr}(\mathrm{III})$ or $\mathrm{Zr}(\mathrm{IV})$ with norfloxacin resulted in the formation of the complexes with the formulas $\mathrm{C}_{32} \mathrm{H}_{44} \mathrm{~F}_{2} \mathrm{~N}_{9} \mathrm{O}_{19} \mathrm{Cr}$ and $\mathrm{C}_{32} \mathrm{H}_{41} \mathrm{~F}_{2} \mathrm{~N}_{6} \mathrm{O}_{9.5} \mathrm{Zr}$.

2. The interaction of $\mathrm{Cr}(\mathrm{III})$ or $\mathrm{Zr}(\mathrm{IV})$ with ciprofloxacin resulted in the formation of the complexes with the formulas $\mathrm{C}_{34} \mathrm{H}_{50} \mathrm{~F}_{2} \mathrm{~N}_{6} \mathrm{O}_{13} \mathrm{Cr}$ and $\mathrm{C}_{34} \mathrm{H}_{44} \mathrm{~F}_{2} \mathrm{~N}_{6} \mathrm{O}_{11} \mathrm{Zr}$.

3. All complexes formed involve direct coordination of the metal ion to quinolones in the ratio of $1: 2$.

4. ${ }^{1} \mathrm{H}-\mathrm{NMR}$ have been used to study the behavior of quinolones and their metal complexes in solution. The spectra of free quinolones were assigned and the chemical shift changes have confirmed the chelate bonding of metal ions to quinolone ring carbonyl and carboxylic oxygens.

5. The decomposition of all complexes proceeds in two steps; the first is the dehydration at low temperatures, which is followed by pyrolytic decomposition at higher temperatures.

6. The zirconium metal complexes decompose over a wider temperature range than the chromium metal complexes.

\section{References}

1. Turel, I., The interaction of metal ions with quinolone antibacterial agents. Coord. Chem. 232, 27 (2002).

2. Curman, D., Zivec, P., Leban, I., Turel, I., Polishchuk, A., Klika, K.D., Karaseva, E. and Karasev, V., Spectral properties of Eu (III) compound with antibacterial agent ciprofloxacin (cfqH). Crystal structure of $\left[\mathrm{Eu}(\mathrm{cfqH})(\mathrm{cfq})\left(\mathrm{H}_{2} \mathrm{O}\right)_{4}\right] \mathrm{Cl}_{2} \cdot 4.55 \mathrm{H}_{2} \mathrm{O}$. Polyhedron. 27, 1489 (2008) . 
3. Turel, I., Golic, L. and Ramirez, O.L.R., Crystal structure and characterization of a new copper(II)-ciprofloxacin (cf) complex $\left[\mathrm{Cu}(\mathrm{cf})\left(\mathrm{H}_{2} \mathrm{O}\right)_{3}\right] \mathrm{SO}_{4} \cdot 2 \mathrm{H}_{2} \mathrm{O}$. Acta Chim. Slov. 46, 203 (1999).

4. Turel, I., Leban, I. and Bukovec, N., Synthesis, characterization, and crystal structure of a copper(II) complex with quinolone family member (ciprofloxacin): Bis (1cyclopropyl-6- fluoro-1,4- dihydro-4-oxo- 7-piperazin- 1ylquinoline-3-carboxylate) copper (II) chloride hexahydrate. J. Inorg. Biochem. 56, 273 (1994).

5. Ruiz, M., Ortiz, R., Perello, L., Latorre, J. and Servercarrio, J., Potentiometric and spectroscopic studies of transition-metal ions complexes with a quinolone derivative (Cinoxacin) - crystal-Structures of new $\mathrm{Cu}(\mathrm{II})$ and $\mathrm{Ni}(\mathrm{II})$ cinoxacin complexes. $J$. Inorg. Biochem. 65, 87 (1997).

6. Ruiz, M., Perello, L., Ortiz, R., Castineiras, A., Mossmer, C.M. and Canton, E., Synthesis, characterization, and crystal structure of $\left.[\mathrm{Cu} \text { (cinoxacinate) })_{2}\right] \cdot 2 \mathrm{H}_{2} \mathrm{O}$ complex: a square-planar $\mathrm{CuO}_{4}$ chromophore. Antibacterial studies. J. Inorg. Biochem. 59, 801 (1995).

7. Macias, B., Villa, M.V., Rubio, I., Castineiras A. and Borras J., Complexes of Ni (II) and $\mathrm{Cu}(\mathrm{II})$ with ofloxacin. Crystal structure of a new $\mathrm{Cu}$ (II) ofloxacin complex. $J$. Inorg. Biochem. 84, 163 (2001).

8. Sadeek, S.A. and EL-Shwiniy, W.H., Preparation, structure and microbial evaluation of metal complexes of the second generation quinolone antibacterial drug lomefloxacin. J. Mol. Struct. 981,130 (2010).

9. Sadeek, S.A. and EL-Shwiniy, W.H., Metal complexes of the third generation quinolone antibacterial drug sparfloxacin: preparation, structure, and microbial evaluation. J. Coord. Chem. 63, 3471 (2010).

10. Sadeek, S.A., EL-Shwiniy, W.H., Zordok, W.A. and EL-Didamony, A.M., Synthesis, spectroscopic, thermal and biologicalactivity investigation of new Y(III) and (III) norfloxacin complexes. J. Argent. Chem. Soc. 97, 128 (2009).

11. Nakashi, K. and Solomon, P.H., Infrared Absorption Spectroscopy, translated into Chinese by C. Wang, Ch. 2. Chinese Academic Press, Peking (1984).

12. Koga, H., Itoh, A., Murayama, S., Suzue, S. and Irikura, T., Structure-activity relationships of antibacterial 6,7- and 7,8-disubstituted 1-alkyl-1,4-dihydro-4oxoquinoline-3-carboxylic acids. J. Med. Chem. 23, 1358 (1980).

13. Goldsmith, J.A. and Ross, S.D., Factors affecting the infra-red spectra of some Planar anions with $D_{3 h}$ symmetry-III. The spectra of rare-earth carbonates and their thermal decomposition products. Spectrochim Acta (A) 23, 1909 (1967)

14. Turel, I., Bukovec, P. and Quiros, M., Crystal structure of ciprofloxacin hexhydrate and its characterization. Int. J. Pharm. 152, 59 (1997).

15. Refat, M.S., Synthesis and characterization of norfloxacin-transition metal complexes (group 11, IB): spectroscopic, thermal, kinetic measurements and biological activity.

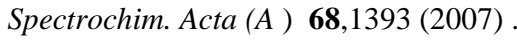

Egypt. J. Chem. 54, No.2 (2011) 
16. Silva-Junior, A.A., Scarpa, M.V., Pestana, K.C., Mercuri, L.P., De Matos, J.R. and de Oliveira, A.G., Thermal analysis of biodegradable microparticles containing ciprofloxacin hydrochloride obtained by spray drying technique. Thermochim. Acta, 467, 91 (2008).

17. Macías Sánchez, B., Martinez Cabarga, M., Sánchez Navarro, A. and Dominguez-Gil Hurlé, A., A physico-chemical study of the interaction of ciprofloxacin and ofloxacin with polivaient cation. Int. J. Pharm. 106, 229 (1994).

( Received 27/7/2011; accepted 8/9/2011) 


\section{توصيف فـيزيـوكيميائى ودراسة طيفية وحراريــة لمتراكبــــات

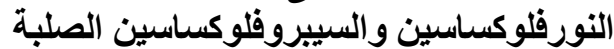

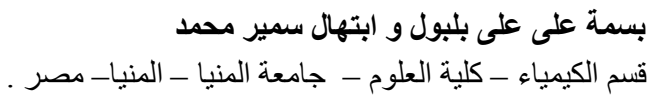

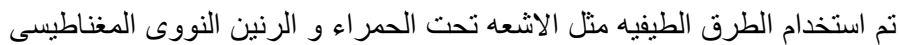

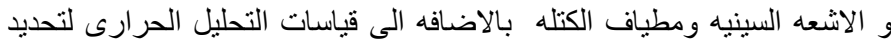

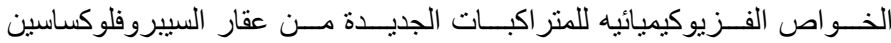

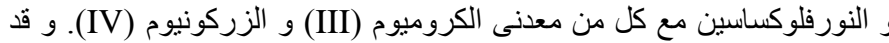
اثبتت النتائج تكوين متر اكبات لها الصيغ مل معلئ البنائيه التاليه :

$\left[\mathrm{Cr}(\mathrm{Nor})_{2}\right]\left(\mathrm{NO}_{3}\right)_{3} \cdot 4 \mathrm{H}_{2} \mathrm{O},\left[\mathrm{Cr}(\mathrm{Cip})_{2}\right] .7 \mathrm{H}_{2} \mathrm{O}\left[\mathrm{Zr}(\mathrm{Nor})_{2}\right] .3 \cdot 5 \mathrm{H}_{2} \mathrm{O}$ and $\left[\mathrm{Zr}(\mathrm{Cip})_{2}\right] 5 \mathrm{H}_{2} \mathrm{O}$.

واوضحت نتائج تحليل الاشعه تحت الحمر اء للمتر اكبات الناتجه ان كل من الأن

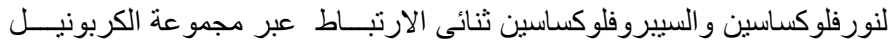

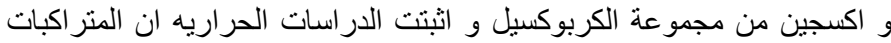

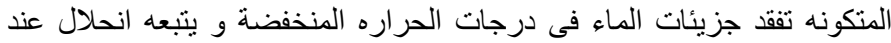

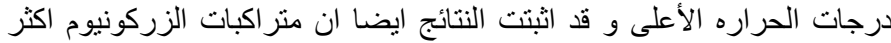

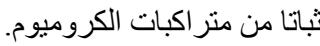

